Pobrane z czasopisma Wschód Europy http://journals.umcs.pl/we

Data: 26/04/2023 13:08:59

DOI:10.17951/we.2018.4.2.13.

Wschód Europy • Восток Европы • East of Europe vol 4, 2 / 2018

Александра Глухова

ORCID ID:https://orcid.org/0000-0002-3894-3229

Воронежский государственный университет, Россия

\title{
Теоретико-методологические проблемы государства в современном политологическом дискурсе
}

C

удьбы национального государства в глобальном мире, роль и значение такого его атрибута как суверенитет, угрозы безопасности и факторы повышения конкурентоспособности стали, в последнее время, ведущей темой в мировом политическом и научном дискурсе. Актуализации проблематики государства способствуют не только резко осложнившиеся международные условия, но и внутренние проблемы многих государств, испытывающих как серьезные экономические трудности, так и легитимационный кризис. В международном сообществе стали появляться различные оценки того, как, опираясь на собственные политико-идеологические традиции и внутриэкономические преимущества, переформулировать роль и значение государства, как снабдить его подходящим конкурентным инструментарием, как вовлечь в массовую политику все более абсентеизирующиеся слои населения.

Концепт государства, как и скрывающаяся за ним политико-правовая реальность, всегда был центральным, базовым понятием политического анализа. Признаки государства, сформулированные М.Вебером ${ }^{1}$,всегда считались классическими и не вызывали серьезных дискуссий. Известный немецкий философ Ю.Хабермас обращал внимание на то, что после Великой французской буржуазной революции 1789 г. территориальное государство, нация и сложившееся в национальных границах народное хозяйство образовали историческое сочетание, при котором «демократический процесс смог принять более или менее убедительную институциональную форму»². Однако сегодня именно единство этих трех элементов, как

1 Суверенитет как исключительный контроль над вверенной ему территорией; выработка законов и правил, регулирующих поведение граждан; монополия на легальное применение силы; право на взимание с населения налогов и сборов и т.д.

2 Ю.Хабермас, Постнациональная констелляция и будущее демократии,„Логос. Журнал по философии и прагматике культуры”, 2003, № 4, с. 107. 
и основанное на них демократическое политическое устройство, подвергается серьезным испытаниям. Государство перестает обладать статусом единственного политического субъекта; нация обнаруживает признаки ослабления единства и гражданской идентичности; хозяйство выходит за пределы национальных границ и все больше ориентируется на глобальный масштаб. Все эти процессы бросают серьезный вызов демократии и фиксируют возникновение новой политической реальности, идентификация которой становится главной задачей общественных наук.

\section{Вызов глобализации}

Возникновение новой реальности обусловлено как объективными, так и субъективными факторами, связанными со способностями правящих элит адекватно воспринимать адресованные государству новые вызовы и давать на них точные и своевременные ответы. Общепризнанно, что ключевым внешним фактором для современных государств выступает глобализация. Она перестраивает власть, функции и полномочия национальных правительств, что особенно ярко проявляется в странах ЕС, где суверенная власть разделена между интернациональными, национальными и местными органами, а также в деятельности ВТО. Но даже там, где суверенитет государства еще не затронут серьезным внешним воздействием, оно больше не обладает исключительным правом распоряжаться тем, что происходит в пределах его собственных границ. Местонахождение власти и субъекты власти могут оказаться как в буквальном, так и в метафизическом смысле слова по разные стороны океана.

Власть и авторитет государства размываются с трех направлений: сверху - интернационализацией; снизу - региональными и местными притязаниями; со стороны - развитием рыночного и гражданского общества, ослабляя его роль в хозяйственном руководстве, социальной солидарности, культуре и формировании идентичности, а также институциональной структуре 3 . Несмотря на то, что государства остаются ключевыми, референтными участниками политического процесса, государствоцентричная парадигма развития не исчерпывает содержания происходящих трансформаций. На первые роли в мировой политике выдвигаются формально не структурированные политические сообщества, функционирующие по сетевому, а не по иерархическому принципу.«Такие группы интересов имеют серьезные преимущества перед традиционными субъектами мировой политики государствами, международными организациями, крупными корпорациями. Они мобилизуют находящиеся в распоряжении этих политических игроков ресурсы влияния, вовлекая представляющие их элиты в систему неформальных сетевых взаимодействий», - отмечают российские исследователич

3 М.Китинг, Новый регионализм в Западной Европе, „Логос. Журнал по философии и прагматике культуры”, 2003, № 6, с. 81.

4 Политические изменения в глобальном мире: теоретико-методологические проблемы анализа и прогнозирования,Научная монография, ред. И.С. Семененко (отв. ред.), В.В.Лапкин, В.И.Пантин, Москва, ИМЭМО РАН, 2014, с. 7. 
Другая серьезная проблема современного государства - это кризис нации как политической общности, что ведет к консолидации региональных сообществ с акцентом на региональные ценности, и одновременно активизации мелких политических единств, более сплоченных, чем национальное государство. Эту двойную тенденцию многие авторы (Р.Робертсон, Э.Гидденс, Р.Дарендорф и др.) весьма удачно обозначили термином «глокализация». Однако новый регионализм, насаждающийся не только с большой интенсивностью, но нередко и насильственно, в отличие от локализма, враждебен демократии, поскольку рождается не из желания демократического самоопределения, а из этнической, языковой или конфессиональной гомогенности. Его первым принципом является отделение: вовне - против «враждебных» соседей, вовнутрь - против не менее «враждебных» меньшинств. Движущей силой развития становится не народное движение, а массовая мобилизация, осуществляющаяся усилиями демагогов и для реализации интересов функционеров. «Результатом ее может стать новая форма „балканизации”», - предостерегал Р.Дарендорф и это предостережение сегодня выглядит очень своевременным ${ }^{5}$.Государство как живой организм и структурная единица Вестфальского мироустройства перестает восприниматься как ценность.Интеграция и фрагментация становятся не взаимоисключающими, а взаимодополняющими процессами перераспределения суверенитета, власти и свободы действий.

Сказанное вовсе не означает исчезновения государства как такового: оно все еще обладает определенным могуществом и роль политических лидеров в мире по-прежнему велика, но природа государства меняется на наших глазах. Сегодня государствам угрожают не столько реальные враги, сколько риски и опасности, что коренным образом меняет их природу. Но это относится не только к государству. «Повсюду мы видим институты, которые внешне выглядят так же, как и раньше, и носят те же названия, но абсолютно изменились изнутри, - отмечает Э.Гидденс. - Мы продолжаем говорить о государстве, семье, работе, традициях, природе, как будто эти понятия остались теми же, что и прежде. Но это не так. Прежней осталась скорлупа, внешняя оболочка, но внутри они изменились... Я называю их „институты - пустышки”. Это институты, уже не соответствующие задачам, которые они призваны выполнять» ${ }^{6}$.

Недееспособность институтов предопределяет настоятельную потребность в их реформировании или создании качественно иных институтов, природа которых еще до конца не ясна. Ситуация, когда мировой капитал приобретает все более глобальную прописку, а юрисдикция остается национальной, требует своего разрешения. Возникает проблема согласования экономических интересов, ориентированных на глобальный рынок, и политико-правовых ограничений,

5 R.Dahrendorf, Auf der Suchenacheinenneuen Ordnung. Eine Politik der Freiheit fur das 21, Jahrhundert, Band, 3. Verlag C.H. BeckoHG, Munchen, 2003, s. 119.

6 Э. Гидденс, Ускользающий мир: как глобализация меняет нашу жизнь, Москва, изд-во «Весь Мир»2004, с.35. 
налагаемых национальным государством. Глобальная экономика, международные структуры, международное законодательство и военно-политические союзы адресуют вызов государственной суверенности. Каждый из них, по мнению Д. Хелда, подрывает или существенно ослабляет государственную монополию на принятие решений в экономической, политической, социальной и военной сферах посредством деятельности различных институтов.

Вместе с тем суверенитет, особенно в юридическом смысле слова, может быть утрачен лишь в том случае, если его место «занимает какая-то другая независимая и (или) „более законная” юридическая власть, которая сокращает правомочное основание для принятия решений в рамках национальной политики» ${ }^{7}$. Отсюда вопрос о том, влечет ли глобализация за собой общее уменьшение или расширение суверенитета, остается открытым.

\section{Ответ популизма}

Сегодня есть основания полагать, что глобалистские тенденции если не прервались на полпути, то, по крайней мере, существенно сбавили обороты. Наблюдается подъем правых сил, возникший как реакция на политико-экономический «зазор» между истеблишментом и обществом, между высшим и средним классом, между политикой, направленной «вовне», и политикой, направленной «вовнутрь» ${ }^{8}$. Этим «зазором» спешат воспользоватьсяпопулисты, выдвигающие лозунги «собственного пути» и «национального суверенитета», привлекательные для широких слоев населения. Вместе с тем популистская риторика, сопровождаемая апелляцией к прошлому, при детальном рассмотрении оказываетсянерелевантной современности,конъюнктурной и невыигрышной по отношению к текущей повестке дня. Предлагаемые ими рецепты -вернуться на полвека назад, разрушить сложившееся союзы и нормативы ЕС, заменить плюралистическую демократию гомогенной и фактически плебисцитарной - не способ решения проблем в XXI веке. Критикуя традиционные политические институты за то, что они не отражают надежды, страхи и озабоченность простых граждан, популисты прибегают к языку демократии, действуя в ее процедурных рамках. Однако цель, по крайней мере некоторых вариантов популизма, заключается в разрушении демократических процессов, в изменении или отмене либеральных ценностей в интересах более значимого блага (как они его понимают). При этом лишь немногие популистские партии имеют программы, охватывающие весь спектр политических вопросов: чаще они концентрируют усилия на нескольких ключе-

Д. Хелд и др., Глобальные трансформации: Политика, экономика, культура, пер. с англ. В.В. Сапова и др.,Москва, Праксис 2004, с. 35.

8 См.: К. Водопьянов, Страдающий Левиафан: что спасет современное государство (о книге Н.Нунан и В.Надкарни «Вызов и изменение. Глобальные угрозы и государство в мировой политике ХХІвека», New York, 2016, 287p.), „Политические исследования”, 2018, № 3, с. 184. 
вых аспектах, вызывающих наибольшие проявления недовольства9. «Популизм воспроизводит наиболее примитивные политические схемы и работает на отрицательную селекцию политической элиты и стратегии развития государства. Кроме того, к числу внутренних угроз следует отнести масштабную коррупцию и прочие внешние, а не национальные интересы политического класса», - считают Н.Нунан и В.Надкарни ${ }^{10}$.

Разрушению государства или ослаблению его институтов способствуют чрезмерная идеологизация внешней политики и тактическое ее подчинение интересам внутренней политики. Проецирование политическим классом собственного взгляда на мир ведет к сужению пространства для маневра в отношении объекта воздействия иподтачивает само государство: у него возникают проблемы с союзниками и традиционными партнерами. Негибкость внешнеполитического курса у элит, принимающих ключевые решения,объясняется отсутствием у них стратегического мышления, аполитикавзвинчивания ставок предельно сужает поле для компромисса, а зачастую ведет к обвальной деградации двусторонних отношений ${ }^{11}$.

Еще более грубой ошибкой, угрожающей деконструкцией государства, становится злоупотребление военной силой, что почти всегда приводит к внешнеполитическому, идеологическому, концептуальному «расползанию» региона применения таких усилий. Hardpowerнеизбежно проигрываетsoftpower, но это не гарантирует от повторения подобных ошибок. Попытки заигрывать с собственным электоратом ожидаемо приводят к бескомпромиссному внешнеполитическому курсу, а успехи во внешней политике «продаются» населению по максимально высокой цене.Это ведет к умножению тактических успехов в ущерб последовательному стратегическому курсу. Отсюда -усиление неопределенности, развитие затяжных конфликтов, многие из которых,в особенности экстрасистемные, возникают из-за «слабых правительств», негодных методов управления, а также из-за ничем не ограниченной борьбы за власть в странах, где элиты заняты, прежде всего, самими собой ${ }^{12}$. Иными словами, основные риски связаны не столько с излишком мощи (как опасались в XX веке), сколько с опасной слабостью многих государств, их неспособностью противостоять разрушающим силам и тенденциям, продуцируемым, в том числе, и неверными или безответственными решениями властвующих элит.

Следует напомнить, что к концу Второй мировой войны государства Западной Европы пришли к заключению, что именно ничем не ограниченное осу-

9 См.: А. Глухова, Популизм как политический феномен: вызов современной демократии, „Политические исследования", 2017, № 4, с. 55 - 56.

10 См.: К. Водопьянов, Страдающий Левиафан: ито спасет современное государство (о книге Н.Нунан и В. Надкарни «Вызов и изменение. Глобальнье угрозы и государство в мировой политике XXI века», New York, 2016, 287p.), „Политические исследования”, 2018, № 3, с. 185.

11 Idem, c. 185.

12 См.: Conflicts in the Century, Lucia Annunziata, Marta Dassu (eds.), Roma, Aspen Institute Inalia 2002. 
ществление государственного суверенитета послужило в XX веке причиной двух мировой войн. «В доме, который они начали возводить для себя в 1950-х - в Европейском Союзе - эти суверенитеты преднамеренно встраивали в пласты правил, норм и инструкций, чтобы они больше никогда не вырвались из-под контроля», - напоминает Ф.Фукуяма ${ }^{13}$. Отсюда большинство европейцев видят главную цель Евросоюза в преодолении политики силы. Таким образом, континент, где зародилась идея современного государства, построенного вокруг централизованной власти и способности к развертыванию военной силы, фактически дезавуировал саму идею государственности как отличительной черты. «Это особенно отчетливо проявилось в Германии, где послевоенная самобытность ... была построена вокруг некоего проекта антисуверенности. С этого времени свобода действий в Германии стала ограничиваться многочисленными напластованиями международных правил, особенно со стороны ЕС, не исключая и другие международные организации, вплоть до $\mathrm{OOH} »^{14}$.

Теоретическим основанием попыток вернуть мир в довоенную эпоху выступает методологический национализм. Он исходит из «естественного» разделения человечества на ограниченное число наций, внутренне организованных как национальные государства, граничащие с другими подобными единствами. Это внешнее ограничение ставится в зависимость от конкуренции между национальными государствами как центральной категории политической организации. «Все современное социологическое мышление и даже все социологическое воображение являются узниками национального государства. И этот методологический национализм затрудняет социальным наукам восприятие процесса космополитизации как в глобальном, так и в европейском масштабе», - считает известный немецкий социолог У.Бек ${ }^{15}$. По мнению автора, методологический национализм не является поверхностным явлением; он затрагивает как частные, так и базовые понятия современной социологии и политической науки, такие как «общество», «социальное неравенство», «классы», «семьи», «занятость», «религия», «государство», «демократия», «социальное воображение».

В российском политическом дискурсе эти новые явления и тенденции замечены и получили определенную оценку, но лишь как побочный фон к внутриполитическим процессам, по-прежнему имеющим определяющее значение. Внешний контекст учитывается преимущественно как вторичный фактор по отношению к происходящему внутри России ${ }^{16}$. Впрочем, в последнее время нередко звучат и иные суждения. Ректор МГИМО академик А.В. Торкунов на заседании Вал-

13 Ф. Фукуяма, Сильное государство: Управление и мировой порядок в ХХІ веке, Москва, АСТ 2006, c. 19.

14 Idem.

15 U. Beck, Europa brauchteinenneuen Traum, Aus Politik und Zeitgeschichte, URL://http://www.bpb. de/apuz/180364+

16 Карт-бланш. Академик А. Торкунов о новом миропорядке,„Независимая газета”, 24. 10. 2014, c. 2. 
Pobrane z czasopisma Wschód Europy http://journals.umcs.pl/we

Data: 26/04/2023 13:08:59

Теоретико-методологические проблемы государства в современном политологическом...

дайского клуба заявил о том, что «Валдайский клуб» для многих - это известный экспертный бренд, но, наверное, пришло время его переформатировать и из российского и внешнеполитического сделать по-настоящему международным. «Новый формат „Валдая” предполагает обсуждение волнующих всех международных проблем без специального акиентирования российской проблематики... (выделено мною - А.Г.)». Но первичность внутриполитических событий как раз и является одним из столпов методологического национализма, поскольку прямо ведет к ключевому для него понятию «суверенитет». Последний же все чаще сталкивается с универсальными, надгосударственными ценностями, записанными в большинстве конституций мира, включая российскую. Именно они ограничивают государство, а фактически правящий режим в его чрезмерных притязаниях. Чаще всего это касается прав человека, но страдающей стороной могут оказаться и другие общественные сегменты: экономика, социальная сфера, культура и т.д.

Между тем прошедшие годы показали: конкурентоспособность в наше время не может быть обеспечена на путях изоляционизма; она требует умелого поиска и нахождения себя в международном разделении труда, в возможности влиять на мировые правила экономического соперничества, в использовании современных технологий и т.д. Принципы послевоенного устройства мира диктуют отказ от насильственной перекройки границ, делая войну неприемлемым способом решения политических проблем. Отсюда - за вычетом военных аспектов суверенитета, заключающихся в сохранении территориальной целостности и безопасности граждан, прочие его аспекты можно считать «стареющим» наследием Вестфальского мира, не вполне релевантным сегодняшнему дню. Интерпретировать мир в категориях прошлых веков, тем более следовать этой картине мира в практических действиях, означает выпадение из современности и обретение страной незавидной участи мирового изгоя.

Выразительный пример - ситуация с вступлением России в ВТО. Российские власти долго убеждали россиян в том, что членство в этой организации не просто необходимо, но и выгодно, поскольку позволяет оказывать влияние на выработку правил мировой торговли. Однако не прошло и полугода после подписания Россией соглашения о вступлении в ВТО, как принцип национального суверенитета, понятый как расширение геополитических сфер влияния, вновь одержал верх над трезвым экономическим расчетом и обоюдной выгодой. Подобные метаморфозы свидетельствуют об импровизационном характере российской внешней политики, дефиците взвешенных решений.

Если крайности методологического национализма будут и дальше диктовать те или иные политические шаги, их последствия могут оказаться очень негативными для страны. Во-первых, уже сегодня в российском политическом дискурce, прежде всего, в его консервативном сегменте - предпринимаются попытки переоценки самого концепта государства. Государство трактуют как нерасчлененное целое; при этом понятие «гражданское общество» как совокупность автономных объединений граждан, сдерживающих чрезмерную экспансию го- 
сударства в сопредельные сферы, аннулируется или трактуется намеренно превратно. Исчезает внутренняя политика как свободная игра политических сил, в ходе которой вырабатывается общенациональный консенсус по наиболее значимым для общества проблемам. Это фактически означает возвращение в XVII в., когда государство и общество воспринимались как единое нерасчлененное целое, а сувереном власти выступал не народ, а абсолютный монарх.

Во-вторых, дифференциация населения страны на «патриотов» и «предателей» прямо нарушает конституционные права и свободы граждан: свободу слова, собраний, демонстраций и т.д. Заодно происходит фактический отказ от важнейшей функции самого государства - обеспечивать социальный мир и общественное согласие. Общепризнанная задача современного государства управление в интересах и к выгоде всех граждан. В силу этого оно обезличено (impersonal), наличие гражданства само по себе гарантирует определенные права и статус, вне зависимости от близости к власти или наличия полезных связей.

B-третьих, принцип суверенитета некоторыми авторами трактуется как неограниченный внешнеполитический авантюризм, игнорирующий принципы и нормы международного права в пользу весьма сомнительной «исторической справедливости», или манипулирующий этими принципами в угоду собственным специфическим интересам.

В-четвертых, публично исповедуемая идеология современных российских консерваторов, включая представителей высшей бюрократии - это конспирологические фантазии, антизападничество, советская державность, культ вождя и показная набожность. Все эти элементы, позаимствованные из разных эпох, эклектично соединены «в одном флаконе». Однако в условиях набирающих силу глобальных штормов стране требуется выверенная мобилизационная стратегия, а не противоречивый идеологический «микс», не релевантный современным глобальным вызовам.

B-пятых, в рамках новой государственной доктрины России право государства на насилие мыслится как первичное по отношению к правам граждан, как основание и источник власти, что позволяет применять его не как последний аргумент, а как превентивную меру. Отсюда - искреннее презрение к идее любых переговоров и «уступок» чьим-либо требованиям, включая самих граждан. Совершенно в феодально-абсолютистском духе некоторые представители российской власти считают, что граждане имеют право лишь просить и подавать петиции. Парадоксальным образом эта позиция считается по-настоящему «государственной». Но в действительности именно злоупотребление монополией государства на насилие ведет к подрыву этой монополии, а, в конечном счете - к подрыву государственности, что наглядно продемонстрировали «арабская весна» 2011 г. и кризис легитимности постсоветских клановых режимов в Грузии, Украине и Армении.

В-шестых, апофеозом методологического национализма становится поголовное увлечение геополитикой, сделавшейся нередко прибежищем откровен- 
Pobrane z czasopisma Wschód Europy http://journals.umcs.pl/we

Data: 26/04/2023 13:08:59

Теоретико-методологические проблемы государства в современном политологическом...

ных шарлатанов. Однако реальным результатом их болезненных фантазий становятся отнюдь не виртуальные, но реальные «гибридные войны» ${ }^{17}$, стоившие многих тысяч жертв.

Природа государства, возникающего в рамках такой парадигмы, может быть только авторитарной. Многократно воспетая стабильность при наличии множества проблем в различных областях жизни лишь подтверждает дефекты подобного общественного устройства, не говоря уже о том, какие риски оно скрывает в себе на будущее. По словам Э.Гидденса, сильным государством раньше считалось такое, которое было хорошо подготовлено к войне. «Сегодня оно должно быть иным: страной, достаточно уверенной в себе, чтобы смириться с ограничением своего суверенитета» ${ }^{18}$.

\section{В поисках выхода}

Современные исследователи эволюции института государства обращают внимание на то, что политическая сфера есть плод исторической эволюции общества.Эта эволюция отражает институализацию государством неконгруэнтных методов в публичной и в латентной сферах, в организации массового дискурса и в процессе принятия решений. «Такой взгляд на динамику политических процессов показывает возможность не только дальнейшего усложнения конфигурации политической сферы (к примеру, в связи с усилением позиций международных игроков на национальных площадках), но и деинституализации отдельных внутриполитических арен (например, в связи с новыми формами взаимодействия online и offline коммуникаций) и даже их исторического полураспада (распада)», - считает известный российский политолог А.И.Соловьев ${ }^{19}$. Следовательно, политические компетенции государства обещают и впредь не упрощаться, но усложняться и множиться, порождая новые, еще более сложные формы взаимосвязей его функциональных граней. Это будет предъявлять все более высокие требования к управленческому искусству правящей элиты, ее коммуникативным способностям и навыкам.

Опасения по поводу эрозии государственного суверенитета, типичные для современных охранителей, исходят из представления о некоем золотом веке, в котором национальные государства якобы обладали абсолютным контролем над своими ресурсами и территорией. Однако подобные представления сильно мифологизированы: суверенная государственность никогда не была абсолютной. Национальные политические сообщества вырабатывают и осуществляют решения, не всегда руководствуясь только собственными интересами, а общество никогда

17 H. Muenkler, Die neuen Kriege, 6. Auflage, Rowohlt Verlag GmbH 2003, s. 285.

18 М. Ноженко, Национальные государства в Европе, Санкт-Петербург, Норма 2007, с. 129.

19 А. Соловьев,Государство как политический институт: проблема теоретической идентификации, Вестник Воронежского госуниверситета, Серия: История. Политология. Социология, 2014, № 4, c. 127. 
не было просто национальным.Напротив, оно всегда было и транснациональным, включало в себя отношения, свободно простиравшиеся за национальные границы и накладывавшие ограничения на суверенитет государств всегда и везде ${ }^{20}$. В частности, уже на ранних стадиях промышленного капитализма стала формироваться система свободного движения труда и капитала; при этом в Европе зоны наиболее бурного развития приходились как раз на приграничные области.

Важно также отметить, что государственный суверенитет является не только правом, но и ресурсом, т.е. набором прерогатив, которыми государство может манипулировать по отдельности. Именно ресурсный потенциал суверенитета и позволяет государствусохраняться, несмотря на вызовыглобализации. Выступая в роли «владельцев суверенитета», государства реализуют его в различных сферах:безопасности, самобытности, самодостаточности, консолидированности и экономической эффективности. Современные государства все больше озабочены именно экономической эффективностью, обеспечением себе достойного места в мировом хозяйстве. Практика показывает, что механизм конкуренции неблагоприятен для тех, кто от нее уклоняется. Новые международные институты не заменяют собой национальное государство, но интегрируют его в транснациональные регулируемые системы. В этой связи засуживает внимания идея У. Бека о замене концепции «эксклюзивного суверенитета» концепцией «инклюзивного суверенитета», предполагающего наличие межгосударственной кооперации, движущей силой которой, тем не менее, останется «государственный эгоизм». Следовательно, речь идет не о разрушении государственного суверенитета, а о признании несостоятельным мифа об его абсолютности.

Таким образом, угрозы суверенитету и состоятельности государства возникают из-за неэффективных методов управления; корыстолюбия властвующих элит, озабоченных собственным обогащением; из-за авантюризма их внешней политики, создающего серьезную угрозу международной безопасности и вынуждающего втягиваться в разорительную для всех гонку вооружений. В современной рыночной экономике глобальная конкурентоспособность оценивается по таким параметрам, как действенность государственной политики, эффективность финансовой системы, качество управления и качество институциональной среды ${ }^{21}$. Вслед за Ф.Фукуямой приходится признать, что институты являются «определяющей переменной процесса развития» ${ }^{22}$, и множество различных экспериментальных исследований полностью это подтвердили.

Не менее значимым представляется соииальный базисконкурентоспособности, от которого зависит развитие интеллекта человека как основного ресурса

20 См.: М.Ноженко, Национальные государства в Европе, Санкт-Петербург, Норма 2007, с. 141.

21 В. Кондратьев,Государство и корпорации в стратегии глобальной конкурентоспособности,,Международные процессы”, 2006, Том 4, № 3 (12), сентябрь - декабрь, с. 18.

22 См.: Ф. Фукуяма,Сильное государство: Управление и мировой порядок в ХХІ веке, Москва, ACT 2006.

Wschód Europy / Studia Humanistyczno-Społeczne 2018 / 4, 2 
Pobrane z czasopisma Wschód Europy http://journals.umcs.pl/we

Data: 26/04/2023 13:08:59

Теоретико-методологические проблемы государства в современном политологическом...

постиндустриального способа производства ${ }^{23}$. Высокое неравенство доходов не способствует росту конкурентоспособности любой страны. Необходима новая социальная политика, которая должна не просто противостоять снижению жизненного уровня, но содействовать его повышению.

Очевидна также связь экономики с публичной политической сферой, с гражданскими свободами. Конкурентоспособность недостижима в отсутствии общественной активности, игнорирования творческого потенциала отдельного индивида, больших социальных групп и слоев. Не случайно, первые строчки в рейтингах Всемирного экономического форума занимают страны с развитой политической системой - Швейцария, США, Германия и т.д. Китай в этом рейтинге занимает сравнительно высокую, 28 позицию, но все-таки не входит даже в первую двадцатку. Россия в этом рейтинге поднялась до 47-го места в 2017 г. Как следует из доклада Всемирного экономического форума, главными препятствиями для развития российской экономики являются монополии и олигополии, блокирующие честную и открытую конкуренцию, препятствующие широкому внедрению инноваций, поскольку не заинтересованы в них или просто не понимают значения вложений в наукоемкие производства.

\section{Выводы}

Современное государство оказывается перед многими серьезными вызовами, заставляющими пересматривать традиционные представления о его природе и свойствах, включая суверенитет и конкурентоспособность. В XXI в. две эти грани государственного существования тесным образом взаимосвязаны, одно невозможно без другого, но и абсолютизировать эти состояния нежелательно. Государство утрачивает статус единственного политического субъекта, суверенитет рассматривается в качестве ресурса в защите национальных интересов, но успех определяется конкурентоспособностью государства, что во многом обусловлено дееспособностью государственных институтов и качеством принимаемых решений. Низкое качество государства подрывает его конкурентоспособность, а значит, и суверенитет.

Суверенитет, зачастую трактуемый в России как безраздельное право государства, а фактически правящего класса делать все возможное для реализации своих корыстно-корпоративных интересов, в корне противоречит установке на активного и автономного индивида, обладающего необходимыми свободами и защищенного правами. Между тем именно от таких индивидов и зависит будущее современных государств.

Сегодня в стратегическом выборе пути развития необходимо следовать тому курсу, которым двигались многие страны и регионы и который обеспечил успешную интеграцию в мировое сообщество. Добиться весомых результатов

23 См.: Ю. Шамрай, Социальный базис конкурентоспособности национальной экономики, „Мир перемен. Международный научно-общественный журнал”, 2014, № 3, с. 77-91. 
Pobrane z czasopisma Wschód Europy http://journals.umcs.pl/we

Data: 26/04/2023 13:08:59

на каком-то ином («суверенном») пути еще никому не удавалось. За дымовой завесой самобытности чаще всего кроются усилия могущественных внутренних кланов, не заинтересованных в открытости страны и ее экономики. Однако в условиях глобализации самоизоляция возможна только ценой отставания и выпадения страны из мировой экономической политической системы.

$\infty$

Аннотация: Современное государство оказывается перед многими серьезными вызовами, заставляющими пересматривать традиционные представления о его природе и свойствах, включая суверенитет и конкурентоспособность. В XXI В. одно невозможно без другого, как нежелательна и абсолютизация этих состояний. Государство утрачивает статус единственного политического субъекта, суверенитет рассматривается в качестве ресурса в защите национальных интересов, но успех определяется конкурентоспособностью государства, что во многом обусловлено дееспособностью государственных институтов и качеством принимаемых решений. Низкое качество государства подрывает его конкурентоспособность, а значит, и суверенитет.

Ключевые слова: суверенитет, конкурентоспособность, глобализация, глокализация, экстрасистемные конфликты, риски, методологический национализм, космополитическая парадигма, инклюзивный суверенитет

\section{Teoretyczne i metodologiczne problemy państwa we współczesnym dyskursie politologicznym}

Streszczenie: Współczesne państwo stawia czoła wyzwaniom związanym ze zmianami w tradycyjnym rozumieniu i postrzeganiu jego natury i właściwości, w tym suwerenności i konkurencyjności. W XXI wieku obie te funkcje są niezbędne - z kilku powodów. Państwo traci status podmiotu politycznego, a suwerenność jest wykorzystywana jako zasób ochrony interesów narodowych. Co więcej, sukces polityczny zależy od poziomu konkurencyjności państwa, oznacza zdolność prawną instytucji publicznych i wysoką jakość decyzji. Niska jakość państwa podważa jego konkurencyjność, a tym samym suwerenność.

Słowa kluczowe: suwerenność, globalizacja, konkurencyjność, glokalizacja, konflikt systemowy, zagrożenia, nacjonalizm metodologiczny, paradygmat kosmopolityczny, integracyjna suwerenność

\section{Theoretical and Methodological Problems of the State in Modern Political Science Discourse}

Abstract: The modern state is challenging with changings in traditional understanding and perception of its nature and properties, including the sovereignty and competitiveness. In the XXI century, both the safe a turesarevital. There are some reasons of it. State loses the political entity status and sovereign tyisused as a resource of the protection of national interests. Moreover, the political success is determined by the level of state competitiveness, it means legal capacity of public institutions and the high quality of decisions. Low quality of the state is undermining its competitiveness and there for a sovereignty. 
Pobrane z czasopisma Wschód Europy http://journals.umcs.pl/we

Data: 26/04/2023 13:08:59

Теоретико-методологические проблемы государства в современном политологическом...

Keywords: sovereignty, globalization, competitiveness, glocalization, extra system conflict, risks, methodological nationalism, cosmopolitan paradigm, inclusive sovereignty

\section{Источники и литература}

\section{Монографии:}

Гидденс Э., Ускользающий мир: как глобализация меняет нашу жизнь, пер. с англ. Москва, 2004. Ноженко М.В., Национальные государства в Европе. Санкт-Петербург 2007.

Политические изменения в глобальном мире: теоретико-методологические проблемы анализа и прогнозирования, отв. ред. И.С. Семененко, Москва 2014.

Фукуяма Ф., Сильное государство: Управление и мировой порядок в XXI веке. Москва2006.

Хелд Д., Гельдблатт Д., Макгрю Э., Перратон Д., Глобальные трансформации: Политика, экономика, культура,Москва 2004.

Conflicts in the Century, Lucia Annunziata, Marta Dassu (eds.), Roma: Aspen Institute Italia 2002.

Dahrendorf R., Auf der SuchenacheinenneuenOrdnung. Eine Politik der Freiheit fur das 21. Jahrhundert. Band 3, Munchen, 2003.

Muenkler H., Die neuen Kriege. 6. Auflage, Rowohlt Verlag GmbH 2003.

\section{Периодические издания:}

Глухова А., Популизм как политический феномен: вызов современной демократии, „Политические исследования", 2017, № 4, с. 49-68.

Китинг М., Новый регионализм в Западной Европе, „Логос”, 2003, № 6, с. 67-116.

Кондратьев В., Государство и корпорации в стратегии глобальной конкурентоспособности, „Международные процессы”, 2006, Том 4, № 3, с. 16-27.

Карт-бланш. Ректор мГИмо Анатолий Торкунов о новом миропорядке, „Независимая газета", 24.10.2014.

Соловьев А.И., Государство как политический институт: проблема теоретической идентификации, „Вестник Воронежского госуниверситета, серия: История. Политология. Социология”, 2014, № 4, c. 124-129.

Хабермас Ю.,Постнациональная констелляция и будущее демократии „Логос", 2003, № 4, с. 105-152. Шамрай Ю., Социальный базис конкурентоспособности национальной экономики, „Мир перемен”, 2014, № 3, с. 77-91.

\section{Интернет-источники:}

Beck U., Europabrauchteinenneuen Traum, Aus PolitikundZeitgeschichte, URL: http://www.bpb.de/ apuz/180364+ (дата обращения: 23.11.2018) 